\section{Inclusion in Vietnam: More than a Quarter Century of Implementation}

\author{
Nguyen Xuan Haia, Richard A. Villab, ${ }^{b}$, Le Van Tac ${ }^{c}$, \\ Jacqueline S. Thousandd, Pham Minh Muce
}

\begin{tabular}{ll}
\hline Received: & 12 September 2019 \\
Revised: & 13 November 2019 \\
Accepted: & 28 December 2019 \\
ISSN: 1307-9298 & Copyright (C) IEJEE \\
www.iejee.com
\end{tabular}

DOI: 10.26822/iejee.2020358219

\begin{abstract}
This article traces the evolution of special education policies and services in Vietnam from their introduction to the current expansion of inclusive education for children and youth with disabilities. Impacts reported include increased educational opportunity for and inclusion of children with disabilities, the development of national policy and provincial and local infrastructures for inclusive education, and capacity building for teachers through preservice, in-service, and master's and doctoral programs expressly designed to prepare personnel to forward inclusive education throughout the country.
\end{abstract}

Keywords: Inclusive Education, International Special Education, Policy Development, Professional Development, Vietnam

\section{Introduction}

Vietnam covers an area of $329600 \mathrm{~km} 2$ and has a population of more than 96 million, which makes it the second most populated country in Southeast Asia. It extends across two climatic zones and has more than $3000 \mathrm{~km}$ of coastline. Ethnically, Vietnam is the most homogeneous country of Southeast Asia, with about $90 \%$ of the population being Vietnamese.

Vietnam also is the most inclusive, in terms of the education of children and youth with disabilities, of all the Asian countries. How did this happen, and where is the country going with regard to inclusive education? In this article, we describe the evolution, since 1991, of special education services in Vietnam, including the process and impact of the introduction and expansion of inclusive education. We describe the steps taken by the Vietnamese Ministry of Education and Training (MOET), Hanoi National University of Education, and international nongovernmental organizations (NGOs) to install inclusive education as a preferred service delivery model for students with disabilities in Vietnam. Six principles are proposed to advance sustainable development of inclusive educational opportunities and supports for Vietnamese children and youth with disabilities.

\section{Origins and Establishment of Special Education Services in Vietnam}

The overall history and evolution of services for students with disabilities in Vietnam parallels that of many other countries in the world. The French colonial government established the first school for Vietnamese students who were deaf in 1886. The year 1975 marks when the Vietnam-American War ended and the country was reunified. In that same year, the Education for All Handicapped Children's Act was enacted by the U.S. Congress, and Vietnam initiated the construction of a special separate school system for students with disabilities. By 1991, Vietnam had established 36 special schools throughout the country, which served 6000 students with disabilities at an expense of $\$ 400$ per year per child compared to $\$ 20$ per year per child without disabilities who attended regular schools.

The seeds of inclusive education in Vietnam were sown nearly 30 years ago. In 1991, Vietnam was the second nation, the first in Asia, to ratify the United Nations (UN) Convention on the Rights of the Child'. In that same year, Vietnam enacted legislation in keeping with the UN Convention on the Rights of the Child that required compulsory primary education and enacted a second piece of legislation that dealt with the protection and care for children. The Law of Protection and Care for Children addressed the reintegration of students with disabilities into society, the availability of special schools, and the provision of rehabilitative services. In 1992, a new constitution was ratified that emphasized appropriate vocational training for children with disabilities.

Despite the supportive national legislation and constitutional changes, in practice, the early identification of children with disabilities, provision of parental support, and student inclusion in preschool, primary, or secondary schools was rare. Vietnamese children with intellectual disabilities, physical disabilities, vision and hearing impairments, deaf blindness, learning disabilities, autism, multiple disabilities, and disabilities resulting from Agent Orange syndrome, disease, and congenital conditions had limited access to any schooling. Traditionally, children with disabilities were cared for by their families, who often viewed the children as burdens to society or sources of shame and pity.

\section{Initial Collaborative Efforts Forwarding Inclusion in Viet-} nam

In response to this prevailing situation, in 1991, the Center for Special Education (CSE) of the Vietnamese National Institute for Educational Sciences began developing and disseminating training materials to support the inclusion of primary school-age students with mild, moderate, and severe disabilities in general education classrooms. The CSE also joined

a Nguyen Xuan Hai, Hanoi National University of Education, Hanoi, Vietnam. E-mail: haiblackocean@yahoo.co.uk

b,* Correponding Author: Richard A. Villa, Bayridge Consortium Inc., San Diego, California, USA. E-mail: ravillabayridge@cs.com

Le Van Tac, Vietnamese National Institute on Educational Science Center for Special Education, Vietnam. E-mail: taccse7@gmail.com

Jacqueline S. Thousand, California State University San Marcos, California, USA. E-mail: jthousan@csusm.edu

e Pham Minh Muc, Vietnamese National Institute on Educational Science Center for Special Education, Vietnam. E-mail: phamminhmuc@yahoo.com 
with Catholic Relief Services (CRS) and other NGOs, such as Save the Children, United Nations Children's Fund (UNICEF), and Sweden's Radda Barnen, to create pilot inclusive education models.

In 1995, the CSE and CRS established the first inclusive education models in two northern Vietnamese districts: Thuong Tin and Tu Liem. The pilot sites were selected because one represented a typical rural community and the other represented a typical urban district. Both were in close proximity to Hanoi, the location of the CSE and CRS offices, and had no existing programs for children with disabilities. An initial activity was to identify the number of students with disabilities, which was a difficult task because students with disabilities traditionally had been excluded from official school-related statistics and were cared for at home. Child-find activities conducted in Thuong Tin and Tu Liem identified 1078 students with disabilities.

Unlike most of the other projects supported by NGOs that focus on the inclusion of children with a specific disability (e.g. students who are blind), CRS Vietnam supported the inclusion of all children, including students with extensive support needs (Villa et al., 2003). The CRS/CSE pilot inclusive education project provided professional learning experiences to administrators, preschool and primary school teachers, and parents of children with disabilities. Training content included rationales for inclusive education, effective multilevel instruction, designing accommodations and modifications, cooperative group learning, student- and family-friendly assessment, and strengths-based individualized educational program planning The CSE personnel also provided technical assistance to students, families, and school personnel in methods for supporting individual students (e.g., mobility training for a student who was blind, range of motion exercises for a child with cerebral palsy). At the local level, project personnel facilitated the establishment of collaborative teams to plan, implement, and evaluate system change activities to establish inclusive educational practices.

In the 4 years following the initiation of the 1995 CRS pilot inclusion project, 1000 of the 1078 identified students with mild, moderate, and severe disabilities were successfully included in general education classrooms in local Thuong Tin and Tu Liem schools. A project evaluation conducted by Catholic Relief Services Vietnam (1998) yielded four major conclusions. First, anecdotal reports from district and local administrators and teachers credited the professional training with prompting major changes in teachers' expectations for children with disabilities and their belief in the feasibility of inclusive education. Prior to the training, expectations for children with disabilities were very limited. Further, teachers reported that, in the past, they did not have the knowledge, resources, or interest in teaching students with disabilities. Anecdotal reports also indicated the training enabled teachers to shift from an exclusively didactic approach to cooperative group learning work with students. A second finding was teachers demonstrated observable increases in their sensitivity to students individual needs. Third, community members voiced positive changes in their attitudes toward the inclusion of children with disabilities in the community and school. Fourth, parents expressed a more optimistic view of their children's future.

High visibility and the success of this pilot helped facilitate policy changes. Specifically, in 1997, a national regulation barring children with disabilities from preschools was abolished. In 1998, Vietnamese law was changed so, for the first time, students with disabilities had the option of attending either special or regular schools. Also, in 1998, MOET shifted its public philosophical stance, stating that up to $90 \%$ of children with special educational needs could be educated in regular schools. It should be noted that the ministry did not identify a specific subgroup or category of disability as unable to have their needs met in general education classrooms. These changes led to the expansion of inclusion efforts described in the following section.

\section{Expansion of Inclusion to Three Additional Provinces}

Given the success of the Thuong Tin and Tu Liem project, in 1998, the CSE and CRS decided to expand their collaborative efforts to develop inclusive schools. They applied for and secured funding from the United States Agency on International Development (USAID) under the Displaced Children and Orphan Fund (Villa et al., 2003). The Expansion of Community Support for Children With Disabilities grant application stated:

Due to limited capacity and distance from the family and community, separate special education programs and classes have not succeeded in educating the vast majority of children with disabilities in Vietnam, keeping them on the fringes of the society in which they will live and compete for resources. (p. 2)

This CSE/CRS grant expanded inclusive options to an additional three provinces: Yen Hung-Quang Ninh, Yen Khanh-Ninh Binh, and Luong Son-Hoa Binh. These three were chosen because of their geographic, socioeconomic, and educational diversity as well as the potential for collaboration among communities and organizations.

Two years into implementation, in November 2000, an external evaluation of the project was conducted by a team including professors from national and local Vietnamese universities and teacher training colleges, three medical doctors from $\mathrm{Vi}$ etnamese pediatric hospitals and clinics, MOET staff, and an international consultant in inclusive education. The evaluation activities were conducted over a 1-week period.

Five sources of data were used in the evaluations: (a) 332 survey questionnaires disseminated to administrators, commune leaders, teachers, and parents of children with and without disabilities; (b) home visits; (c) in-depth group interviews; (d) individual interviews conducted with 28 parents of students with disabilities, 20 teachers, nine parents of students without disabilities, and nine principals; and (e) evaluator field notes. Data collected across the three provinces resulted in approximately 17 hours of classroom observations, 10 hours of audio-taped interviews, and more than 500 pages of survey questionnaires. The evaluation team documented the impact of the Expansion of Community Support for Children With Disabilities project in the six areas described next.

\section{Impact 1: Community Awareness and Support for Children With} Disabilities

Community members surveyed and interviewed by the evaluation team indicated that, following participation in project activities, the caring for and supporting of all children, including children with disabilities, clearly became viewed as the responsibility and desire of the community. For example, commune leaders facilitated public awareness campaigns in local newspapers and radio stations. Communes worked through their women and farmer unions to raise funds for schooling children with disabilities.

Impact 2: Development of Local Infrastructures for Inclusive Education

The evaluation team determined, as a result of project activities, a strong infrastructure supportive of inclusive education had developed at province, commune, and school site levels (Villa et al., 2003). Community steering committees comprised of personnel from district education offices, community religious leaders, representatives from the Women's Union and the Farmer's Union, Red Cross, and the Communist Party were established in each community. Members eagerly expressed their desire to support all children in their districts, including children with disabilities. Commune leaders described specific ways in which they actively supported children with disabilities 
and their families (e.g., securing wheelchairs and walkers, providing tuition assistance) because of project activities. The project established steering committees, which then built the infrastructure critical for demonstrating sustainable inclusive communities, schools, and classrooms.

Impact 3: Inclusive, Age-Appropriate Placement in Natural Proportions

As children with disabilities were being brought into general education classrooms, every effort was made to ensure they were placed within 1 to 2 years of their chronological age. Prior to the project, students with disabilities who had been given opportunities to attend school frequently were placed in classrooms with much younger children. Consequently, the concept and practice of age-appropriate placement was a major steering committee intervention outcome.

Paralleling the age-appropriate placement outcome was the introduction and implementation of the natural proportion principle (i.e., the principle that the percentage of children with disabilities in a given class should be no greater than the overall percentage of children with disabilities in the general population). Classroom observations, interviews, and survey results indicated, in every case, the natural proportions criteria were observed when students with disabilities were placed through committee and project efforts in the three provinces.

Impact 4: Improved Quality of Teaching and Attitudes Toward Children With Disabilities

Prior to the project, there had been minimal in-service education of any sort. As a result of participating in inclusive education training, community leaders and teachers described: (a) increased activity-based instruction and interaction among teachers and their students, (b) students exploring new ideas via cooperative learning, (c) positive changes in teacher and classmate attitudes and feelings about children with disabilities, and (d) an increased perception that all children should be valued members of a classroom.

\section{Impact 5: Increased Family Support}

Affording students with disabilities the opportunity to attend inclusive classes made a positive difference in the lives of families with children with disabilities. For example, the mother of a preschooler with cerebral palsy shared her son, Bon, woke up every morning excited to go to school. She told how he could sit longer and pay attention to both his lessons and his peers. When asked about her expectations and dreams for her son, she shared she now wanted her son to learn to read and write. She said his access to school, trained teachers, and friends had made his and her life happier.

An elder in one village was the grandfather of a primary school-age boy, Thang, who had a disability. This grandfather laughed with joy when he shared his grandson comes home and "relives the lessons every day." He expressed great pride for his community's efforts to improve the quality of his family's life and the lives of families of children with disabilities in their commune.

Impact 6: Overall Improvement in the Educational Lives of Children With Disabilities

At the start of this expansion project in 1998, only $27 \%$ (1 304) of the nearly 5000 preschool and primary school-age children with disabilities in these three provinces attended regular preschool and primary school classrooms. By the end of 2000, an additional 3000 students with disabilities were attending regular classes, with $86 \%$ (4 300) of students with disabilities attending regular classes. Only 588 (14\%) of the student population with disabilities were not yet in school. A USAID-approved grant extension allowed the continuation of the expansion project through 2003, enabling project activities to spread to an additional six districts, resulting in 5000 additional students with disabilities being educated in local schools of these six additional districts and the establishment of inclusive education as the primary service delivery model in 10 of Vietnam's 63 provinces in a brief 8 -year period. At the time, the per-pupil cost of educating these students with disabilities averaged $\$ 58$ per year compared to the $\$ 400$ average for services in segregated schools and the $\$ 20$ average for general education students. Clearly, inclusive education had been demonstrated to be cost effective.

In summary, the combined activities of the pilot and expansion projects directly contributed to the education of thousands of students mentioned previously and thousands of additional students with disabilities throughout the country who were included because of the legislative and policy changes, teacher and leadership preparation initiatives, and use of training materials and practices developed by the projects.

\section{Movement Toward Inclusive Education as the Preferred Mode of Education for Children With Disabilities}

As with all system change endeavors, sustained commitment and eternal vigilance is required to maintain any progress that has been made, address barriers such as those cited previously, and expand inclusive opportunities countrywide. Vietnam has made such a public commitment to inclusive education, and MOET led the way.

\section{0-2005: MOET Leadership Introduce Inclusive Education Na-} tionwide

To operationalize its commitment to inclusive education, MOET established four goals to advance inclusive education in 2000:

1. By 2005 , across the nation, $60 \%-70 \%$ of children with disabilities in urban and "advantaged" areas and $40 \%-50 \%$ of children with disabilities in rural or "disadvantaged" areas would receive their education in general education classrooms with typical age-appropriate peers.

2. Students in special schools would be transitioned to community schools, and the role of personnel in special schools would be redefined so they function as trainers, technical assistance providers, program evaluators, and consultants.

3. Cadres of teacher educators would be prepared at the national, district, and school levels to provide ongoing training and technical assistance to local school personnel.

4. The teacher preparation curriculum would be modified to ensure teachers acquired skills to educate a diverse student body.

As an initial action, MOET directed each of the country's 63 provincial education departments to develop a plan for achieving these four goals. To support the development and implementation of the provincial plans, MOET provided workshops for teachers and university leaders alike. In 2001, workshops for deans and/or vice deans and other leaders of teacher training institutions were conducted in 61 cities and provinces across Vietnam. In 2002, in-service workshops were delivered to incumbent teachers and school directors at the local level through three pedagogical institutions, which also piloted new "best practice" preservice primary 
teacher education programs. The MOET also developed best practice materials for use by university faculty to prepare teachers of preschool and primary school-age children with disabilities.

By 2004, training had been provided to all key pedagogic professors and national pedagogical leaders on inclusive education for preschool- and primary-age children. Activities also were initiated to transform local special schools, so personnel who previously served children in segregated settings were equipped to provide outreach and technical assistance in the local community schools. Also, up to and through 2004 an additional 1200 teachers received in-service training on how to implement inclusive educational practices. Additionally, selected candidates from provincial pedagogical colleges and special schools received 2 years of specialized baccalaureate-level training in inclusive educational practices, with the goal being these professionals would become leaders who could sustain the project's work at the local level when the grant was finished.

2005-2019: Standards, Policies, and Professional Learning to Advance Inclusive Education

Until 2005, the primary focus of inclusive educational activities and training had been at the preschool and primary school levels. Vietnamese governmental agencies, however, knew and understood the need to forward inclusion at the secondary education level as well. In addition, it was understood, if inclusive education was to spread throughout Vietnam for students of any age and grade level, standards of quality for inclusive education needed to be developed and implemented; laws, policies, and procedures supportive of inclusive education needed to be established; and professional preparation of educators needed to include pedagogy on how to adapt curriculum and instruction for a more diverse student population that includes students with a wide range of learning differences and identified disabilities.

What follows are descriptions of the initiatives to establish standards of quality, laws and policies, and professional learning opportunities to advance inclusive education as the preferred mode of education for students with disabilities in Vietnam.

Collaborative efforts to promote the quality of inclusive education through the development of standards

In April of 2012, MOET embarked on a joint venture with faculty of Hanoi National University of Education (HNUE) to develop a set of standards and criteria for guiding and assessing the quality of inclusive education for children with intellectual disabilities in preschool, elementary, and secondary schools. It was recognized that teachers and institutions likely had less knowledge and experience adapting curriculum and instruction for students with intellectual disabilities, as they largely had not been to school prior to the initiation of the inclusion pilot and expansion projects described previously. The eight standards of quality and accompanying 46 criteria that were developed were based upon inclusive educational best practices that had been researched and published primarily in the United States (e.g., setting individualized learning goals in a group learning process, specification of a core curriculum, competence-based assessment of learners that measures individual progress instead of one-off standardized testing). The desired outcome of having a set of inclusive education standards was to not only improve the quality of education for children with intellectual and other disabilities but to provide educational institutions and administrators with the practices and polices they needed to lead the redesign of their schools organizational structures, policies, and instructional practices.

To get the standards into the hands of provincial school administrators, from 2013 through 2016, MOET held conferenc- es that disseminated the standards in Hanoi, Ho Chi Minh City, and other provinces, such as Da Nang, Ninh Binh, Ninh Thuan, and Quang Ngai. Standards also were disseminated in 2015 at international conferences (e.g., Asia-Pacific Disability Forum in Hanoi, International Workshop on Inclusive Education in Osaka, Japan). The standards and related content were integrated into the coursework for students studying special education at HNUE and Hanoi's National College of Education, particularly in the courses related to policy, strategic action planning and management, special education, and inclusive education.

As a result of these collaborative efforts, educator and administrator awareness of the need to assess and ensure the quality of inclusive education for children with disabilities, particularly those with intellectual disabilities, has increased. Several schools, especially Hanoi schools affiliated with HNUE, have used the standards and criteria to assess and take action to improve the quality of inclusive experiences for their students with intellectual and other disabilities and initiate organizational change in alignment with the standards. The number of children with disabilities, particularly intellectual disabilities, attending and being more involved in academic learning activities in the inclusive classrooms of these schools has increased, and the work of this initiative was translated into policy with the June 22, 2016 MOET Decision Number 23 regulations that articulate the responsibilities of teachers and administrators of preschool and general education institutions regarding inclusive education for students with disabilities. This is one of several national policies, featured and described in Table 1, that MOET issued to provide and expand upon the legal framework for national management mechanisms to install inclusive education in Vietnam.

\section{Law and policy development forwarding inclusive education}

As reported in the first large-scale, comprehensive national survey on people with disabilities (General Statistics Office, 2018) conducted in 2016 and 2017, national law and policy have systematically established a clear proinclusive legal framework, explicitly articulating the rights of children with disabilities to a quality education as well as clear roles and responsibilities of all actors in the educational system. This finding is evidenced by the chronology of key laws and policies set forth from 2006 through 2019 presented in Table 1.

These laws and policy circulars both adopt inclusion as an organizing principle of how educational services for children with disabilities are to be structured and delivered and mandate coordinated efforts to increase the capacity of teachers and administrators to structure the education of children with disabilities in inclusive classrooms. To illustrate, MOET's comprehensive January 2018 Decision 338 Education Plan for People With Disabilities (see Table 1) builds upon the previously cited four goals (for 2005) and increases inclusive education targets for 2020 to:

1.Seventy percent of preschool and school-age (i.e., elementary and secondary) students with disabilities accessing quality equitable education,

2.Fifty percent of all educators and administrators having received professional learning experiences to successfully educate students with disabilities,

3.Forty percent of the 63 provinces having an operational Center for Inclusive Education Development resource center providing schools with technical assistance and training, and

4.One hundred percent of provincial governments fully aware of and initiating implementation of national guidelines and regulations on the education for persons with disabilities (summarized in Table 1). 
Table 1. Landmark National Laws, Policies, Regulations, and Circulars Advancing Inclusive Education in Vietnam Since 2006

Decision No. 23 (June 22, 2006). MOET issues regulations on the responsibilities of teachers and administrators and preschool, elementary and secondary general education institutions on inclusive education for children with disabilities.

Vietnam Law on Disabilities, Chapter IV. Education, Articles 27 -31 (2010). National legislation mandating staffing for educational support of children with disabilities within Vietnamese schools; the establishment of provincial Support Centers for Inclusive Education; development of resource centers that provide technical assistance and training to schools; the responsibilities of teachers, administrators and educational institutions; and the provision of needed educational materials for students with disabilities (e.g., materials in Braille for students who are blind). Inclusive education is emphasized as the main mode of education for children and youth with disabilities.

Decree No. 28, Article 7, Item 2. (April 10, 2012). Teachers educating students with disabilities in inclusive classrooms receive $20 \%$ additional salary.

Circular No. 58 (December 28, 2012). MOET and the Ministry of Labor, Invalids, and Social Affairs (MOLISA) stipulate the procedures for establishing, operating, and organizing centers for inclusive education that provide technical support to schools.

Circular No. 42 (December 31, 2013). MOET, MOLISA, and the Ministry of Finance (MIF) articulate policies regarding educational rights of individuals with disabilities including adaptation of curriculum and activities; university studies; and financial support for school supplies, equipment, and scholarships to allow for participation in education.

Circular No. 19 (June 22, 2016). MOET and Ministry of Homeland Affairs (MOHA) establish a new job code for the training of staff (e.g., teachers) that supports the education of individuals with disabilities in educational institutions.

Circular No. 16 (July 12, 2017). MOET issues guidelines for jobs and numbers of educators working in public general education establishments, which includes staff to support the education of individuals with disabilities in educational institutions.

Circular No. 3 (January 29, 2018). MOET issues regulations regarding inclusive education for persons with disabilities, which specifies responsibilities of teachers and administrators to keep information regarding children with disabilities confidential and their responsibilities and rights in implementing competency-based educational reform. This circular also describes establishing within educational settings the resources-materials, specialized equipment, assessment checklists to determine student's abilities, counseling technical assistance personnel-to enable educators to support students with disabilities in their schools and classrooms.

Decision 338 (January 30, 2018). MOET issues the comprehensive Education Plan for People with Disabilities for the 2018 - 2020 time period to advance implementation of inclusive education nationwide.

Decision 2913 (August 10, 2018). MOET issues 5 detailed syllabi and accompanying guidelines for inclusive education modules for preschool, primary, and secondary teacher training programs in Vietnamese colleges and universities.

Decisions 1438 (October 29, 2018). The Ministry of Government issues goals for the 2018-2020 and 2021-2025 time periods to further advance protection, care, and education of children with disabilities in provincial communities nationwide.

Vietnam Law on Education, Article 15. Inclusive education (2019). For the first time, national education law identifies inclusive education as the preferred mode of education and states that the State shall adopt policies to support the implementation of inclusive education.

In October of the same year, the national government, through Decree 1438 (also listed in Table 1) established phased goals over the 2018-2025 time period to advance the inclusion of children with disabilities not only in education but in protection and care services of local communities. Culminating goals for 2025 include:

1.Ninety percent of children with disabilities having access to protection, care, and educational services;

2.Eighty percent of parents and caregivers having been provided knowledge and skills to support children with disabilities to access community protection, care, and educational services;

3.Local staff of social organizations and institutions having been provided with knowledge and skill to facilitate community protection, care, and educational services for children with disabilities; and

4.Ninety percent of the 63 provincial governments establishing and linking pilot models of support for children with disabilities to protection, care, and educational services in the community.

Finally, the most recent 2019 Vietnam Law on Education, Article 15 , for the first time identifies inclusive education as a preferred mode of education and expressly states, as a mode of education, it (a) respects diversity, learners' needs and characteristics, and meets differing needs and abilities of learners; (b) ensures equal learning rights and quality; and (c) is nondiscriminatory. Further, the law commits Vietnam to the continued development of policies that support the implementation of inclusive education for children with disabilities according to the provisions of the 2010 Law on Disability and other relevant laws and regulations.

In summary, as the aforementioned goals of recent decisions and law illustrate, Vietnam's current thrust is the sustainable development of inclusive services and education opportunities in communitites nationwide.

\section{Professional preparation for inclusive education}

Developing the capacity of teachers to use instructional strategies, school administrators to organize the structure of the day, and resources to be conducive to inclusive classrooms requires ongoing in-service training and support (e.g., through provincial Support Center for Inclusive Education Development resource center technical assistance and training), re-education of teacher educators and local and regional educational leadership personnel at institutions of higher education, and a revamping of teacher preparation curricula. Vietnam's efforts to accomplish the first twoteacher in-service training and support and the re-education of educational leadership-have been described previously and are ongoing. What has not yet been described are the efforts in preservice preparation on inclusion as a requirement for teacher certification and the establishment of new master's and doctoral programs in inclusive special education. 
Infusing inclusive education principles and practices into preservice preparation programs

Currently, every preschool teacher in preparation is required to complete a 45 -hour course on inclusive principles and practices to obtain teaching certification. Numerous programs preparing elementary and secondary teachers have also adopted this course as part of their curriculum. As noted in Table 1 , teachers who educate children with disabilities in their inclusive classrooms receive $20 \%$ additional salary.

\section{Master's program in inclusive special education}

Following a 2011 MOET decision supporting the initiation of a master's program in inclusive special education, the faculty of special education at HNUE started the first master's degree program to provide educational professionals with additional instruction in special education and inclusive education principles and practices that qualify them to work in a variety of private and public educational institutions (provincial Support Centers for Inclusive Education Development, colleges, schools) and human service settings where children with disabilities are being educated and receiving other services. Candidates who have entered the program have backgrounds in general education, special education, psychology, social work, health, and social science professions. As candidates, they have a choice of two program options-one that focuses on practical instructional and other support skills and a second that provides candidates with additional research skills. In both options, candidates complete a series of core compulsory courses, choose a specialty concentration, and produce a culminating project/thesis. The average time to completion for candidates is 2 years. As of October 2019, 142 candidates have completed one or the other of the programs. An additional 16 will finish in 2020. The authors of this article have had the privilege of instructing candidates in these programs and are most impressed with their enthusiasm, creativity, technical expertise, and vision of inclusion for Vietnam.

\section{Doctoral program in special education}

With a 2018 MOET decision supporting the initiation of a doctoral program in inclusive special education, the faculty of special education at HNUE again have taken up the call and are opening its doors to the first Vietnamese special education doctoral candidates.

\section{The Current State of the Education, Life, and Attitudes To- ward Individuals With Disabilities in Vietnam}

As already mentioned, in late 2016 and early 2017, the Vietnamese General Statistics Office conducted the first largescale, comprehensive survey to examine the life of individuals with disabilities living in Vietnam. The study, Vietnam National Survey on People With Disabilities (General Statistics Office, 2018), was administered with 35422 households across all 63 provinces of the country. The purpose of the survey ${ }^{2}$ was to identify people with disabilities, to assess their education and socioeconomic conditions, and to provide data for planning and improving the lives of Vietnamese citizens with disabilities.

Survey results revealed $7.06 \%$ of the population (age 2 and older) as having a disability and $2.83 \%$ of children ages 2 through 17 as having a disability. It should be noted that the majority of students identified as having a disability in Vietnam are students who would be considered as having moderate to severe disabilities in the United States; students with mild disabilities, such as learning disabilities, are not, for the most part, identified as having a disability.

\section{Positive Findings Related to Inclusive Education}

The national survey found $94.2 \%$ of students identified as having a disability were being educated in general education classes. ${ }^{3}$ Nearly half the students with disabilities were identified as having intellectual disabilities. In 2016, the average number of students with disabilities per school was 8.3 persons. Only $0.5 \%$ of children with disabilities were educated in special classrooms, and only $1 \%$ were educated in special schools. The one exception was children with hearing difficulties: Nearly $26 \%$ of these students attended a special classroom.

\section{Continuing Barriers to Inclusive Education}

As in all countries attempting to provide inclusive educational opportunities for their citizens with disabilities, there are barriers yet to be overcome. As already suggested, educational policies, structures, and practices supportive of inclusive education have yet to be implemented throughout the country. Additional barriers identified by the survey are continued discrimination, lack of equitable educational opportunities, and uneven teacher professional development.

Discrimination. Discrimination against people with disabilities remains a serious barrier to their participation in society. Only $42.7 \%$ of all survey respondents believed children with disabilities should attend school with nondisabled children. Younger respondents tended to be more progressive than older ones, with more than $46 \%$ of people under the age of 30 believing children with disabilities should attend "normal" school, compared with $38.5 \%$ of those over the age of 60 .

Lack of equitable educational opportunity. Survey results revealed accessible opportunities to schools for children with disabilities are much lower than for nondisabled children. Namely, the net school enrollment rate for children with disabilities is $88.7 \%$, while the rate for nondisabled children is $96.1 \%$. The gap in this rate among children with disabilities and nondisabilities increases at the upper secondary level, where only $33.6 \%$ of children with disabilities attend school compared with $88.6 \%$ of nondisabled youth.

The lack of educational opportunity for and support of children with autism is of particular concern in Vietnam. The Protection Association of Children's Rights (2016) has found the number of Vietnamese children identified as experiencing autism has rapidly increased, yet these children and their families receive little support because autism is not yet identified as a disability category within the law. ${ }^{4}$ Results of surveys and interviews of 10 school leaders, 269 teachers, and 120 parents of elementary-age children with autism (Muc, 2019) revealed large numbers of children with autism are not attending school, and, when they do, teachers and family members agree school personnel have not received adequate training and support. Participants in the study called for training for teachers and families, cross-disciplinary collaboration, and policies and practices that recognize autism as a disability and provide the needed educational support.

Uneven teacher professional development. Also found in the report was nearly three quarters (72.3\%) of schools still lacked teachers qualified to teach students with disabilities. For every seven teachers in primary and lower secondary schools, only one teacher $(14.1 \%)$ thusfar has received training to educate students with disabilities.

Six Principles for Sustaining Development of Inclusive Education in Vietnam

Hai (2019), the developer of the master's and doctoral programs at HNUE, a researcher who has closely followed the emerging policies and practices of inclusive education in Vietnam, and coauthor of this article, proposes six principles represented in the star configuration in Figure 1 for guiding future actions to sustain development of inclusive education in Vietnam. 
Principle 1. People With Disabilities Are the Center of Sustainable Development

To sustain the development of inclusive education, individuals with disabilities need be at the center of thinking to ensure basic human needs and rights (safety, participation, belonging, respect, opportunities for personal development) common to all individuals are considered and addressed. All citizens have a right to equal opportunity for development in society, to access general resources, and to get public benefit to create knowledge and culture for future generations.

Principle 2. Policies Supportive of Inclusive Education Underpin Inclusive Practice

National policies on the education of persons with disabilities provide national, provincial, and local organizations and governmental agencies direction for supporting inclusive education. The implementation of policies for inclusive education need to meet the real needs of persons with disabilities in their own lives, have financial and human resource backing to actually implement inclusive education with quality and effectiveness, and clarify the roles and responsibilities of local governments, agencies, and schools for regulations to have the desired impact on intended benificiaries.

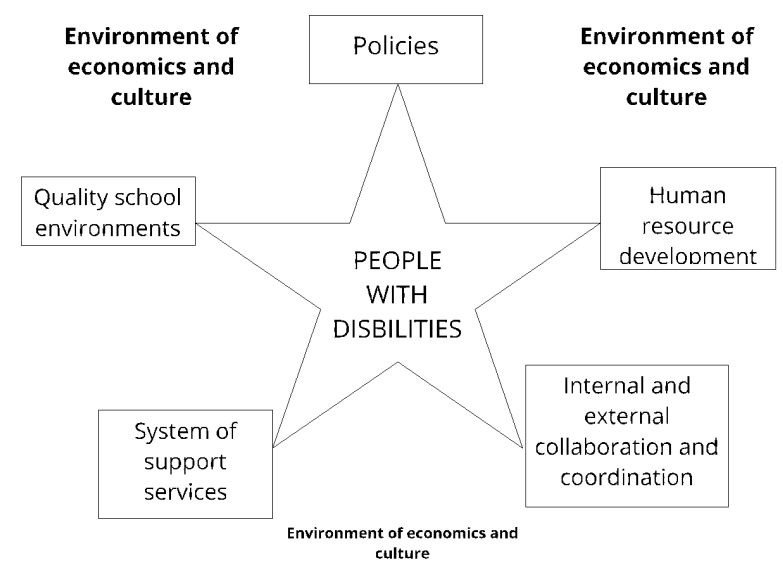

Figure 1. Six principles for guiding sustainable development of inclusive education in Vietnam.

Principle 3. Human Resource Development Is Essential for Sustainable Development

Educational personnel at all levels-general education classroom teachers, special education support personnel, school and provincial administrators, university faculty, researchers-need opportunities to examine and develop their professional values, knowledge, skills, and relationships with one another to become proficient at conceptualizing and constructing inclusive learning experiences for students with disabilities. Human resource development requires the development of standards of practice, job descriptions for existing (e.g., inclusive classroom teacher) and emerging (e.g., special education support personnel) positions, and standards for teacher preparation programs at universities and colleges. Adequate personnel preparation also means educational institutions (e.g., provincial Support Centers for Inclusive Education Development) are proactive in developing and providing in-service training for educators and families of children with disabilities.

Principle 4. The Overall Quality of School Environments Must Be Examined and Improved

Children with disabilities are more likely to be welcomed, valued, and successfully educated in schools that are quality learning environments for all children, with and without disabilities. To determine what organizational structures, policies, and instructional practices need to be improved and redesigned in schools, evaluation of current practices needs to occur. The inclusive education quality assurance standards and criteria jointly developed by MOET and NHUE in 2012 for children with intellectual disabilities are a good starting point for increasing public understanding of the need to assess the quality of school environments. Examining and improving overall school environments across a broad spectrum of cultural, psychological, and pedagogical factors-safety, respect of differences, nondiscriminatory practices, adult and student collaboration, "best practice" teaching and learning methods, family and community involvment-go hand in hand with instilling and installing inclusive education best practices.

Principle 5. A System of Support Services Is Essential for Sustainable Development

For inclusive education to flourish, resources must continue to be allocated, reallocated, and expanded. Despite the fact that most (94.2\%) students identified as having a disability receive their education in an inclusive classroom, a significant percentage of elementary-age (11.7\%) and upper secondary-age (66.4\%) students with disabilities and students with autism of all ages still are not attending school. Clearly, systems of supports need to be developed and expanded to address the needs of these students and those already attending school. Currently, support services (e.g., Support Centers for Inclusive Education Development) in several of the 63 provinces and university teacher preparation programs are available in an increasing number of communities; however, a comprehensive system of supports has yet to be extended to all communities, particularly those in the most rural regions of the country. The MOET, the Ministry of Finance, and other governmental agencies have important continuing roles to play to ensure the number and quality of human resources, material, and technical resources needed across the country are both identified and deployed in planful and systematic ways.

Principle 6. Collaboration and Coordination Is Needed Among Internal and External Organizations

"Collaboration is to education as location is to real estate."

The two U.S. coauthors of this article are fond of making this American comparison or analogy to emphasize the importance of collaboration in most every educational endeavor. Collaboration and coordination of effort among national, provincial, local community (e.g., commune), and school levels were the keys to getting the first inclusive education pilot models started in the early 1990s, and Vietnam benefitted greatly from collaboration with NGOs (e.g., Catholic Relief Services) external to the country to provide both expertise and initial model demonstration funding. Therefore, the sixth and final guiding principle for guiding future actions to sustain development of inclusive education in Vietnam is to remember collaboration sparked this inclusive education movement, and collaboration, creativity, and coordination of funding, policy, and action among all levels of internal educational and governmental levels and current and future external partners will carry it forward to achieve the 2020 and 2025 goals and beyond.

\section{Conclusion}

As of the publication of this article, Vietnam has had 28 years of experience with planning for and taking action to establish inclusive education as the preferred service delivery model for students with disabilities The progress that has been made in this time is remarkable, yielding outcomes that position Vietnam as the most inclusive, in terms of the education of children with disabilities, of all Asian countries. New laws and policies in support of an inclusive educational vision and inclusive educational practices have been put into place with impressive speed. Furthermore, the Viet- 
namese Ministry of Education and Training has taken steps to transform global thinking into local action by directing and supporting the 63 provincial education departments to take ownership for and implement the ministry's national regulations and guidelines on the education for persons with disabilities to achieve its 2020 goals of increasing the numbers of educational personnel trained, provincial technical assistance resource centers installed, and preschool through secondary students with disabilities receiving an equitable quality education. The Vietnamese vision of inclusive education has been articulated and combined with the development of skills, provision of incentives, allocation of resources, and an action plan developed by the Ministry of Education and Training. There is much other countries can learn from the Vietnamese inclusive education experience.

\section{Footnotes}

${ }^{1}$ The United States is the only member nation of the United Nations that has not yet ratified the UN Convention on the Rights of the Child.

${ }^{2}$ To identify disabilities for children ages 2 through 17 years, the survey used the Disability Identification Tool of the Washington Group on Disability Statistics and the Washington/ UNICEF tool.

${ }^{3}$ As a comparison, the United States currently serves $62.7 \%$ of its students with disabilities in general education classrooms for $80 \%$ or more of their day (U.S. Department of Education, 2017).

${ }^{4}$ When children with autism are identified, provincial health facilities make the determination and their disability is listed as Other Disabilities.

\section{References}

CRS Vietnam. (1998, March). Mid-term review of inclusive education in Thuong Tin District, Ha Tay Province (pp. 8-12). Hanoi, Vietnam: Author.

General Statistics Office. (2018). Vietnam National Survey on People with Disabilities 2016 [Final report]. Hanoi, Vietnam: Statistics Publishing House.

Hai, N. X. (2019). Sustainable development and its model of inclusive education for persons with disabilities in Vietnam. Journal of Science, 64(9), 55-65.

Muc, P. M. (2019). Inclusive education for students with autism spectrum disorder in elementary schools in Vietnam: The current situation and solutions (Unpublished manuscript). Hanoi, Vietnam: Vietnamese National Institute on Educational Science, Center for Special Education.

Protection Association of Children's Rights. (2016). Reality of ensuring the rights of children with autism spectrum disorders and some policy recommendations: A research report. Hanoi, Vietnam: Author.

U.S. Department of Education. (2017). 39th annual report to congress on the implementation of the Individuals With Disabilities Education Act. Washington, DC: Author.

Villa, R. A., Tac, L. V., Muc P. M., Ryan, S., Thuy, N. T. M., Weill, C., \& Thousand J. S. (2003). Inclusion in Vietnam: A decade of implementation. Research and Practice for Persons With Severe Disabilities 28, 23-32. doi:10.2511/ rpsd.28.1.23 